\title{
A new gas-medium, high-pressure and high-temperature deformation apparatus at AIST, Japan
}

\author{
Koji Masuda, Koichiro Fujimoto, and Takashi Arai \\ Institute of Geoscience, National Institute of Advanced Industrial Science and Technology, AIST Tsukuba Central 7, Tsukuba 305-8567, Japan
}

(Received December 30, 2001; Revised September 30, 2002; Accepted September 30, 2002)

In order to obtain information about the deformation and fluid-flow processes in seismogenic regions, we designed and constructed an original Japanese-type gas-medium deformation apparatus capable of achieving both high pressure and high temperature. The present apparatus can produce a basic environment in which the confining pressure reaches $200 \mathrm{MPa}$ by argon gas, pore pressure reaches $200 \mathrm{MPa}$ either by argon gas or water, and temperature reaches $800^{\circ} \mathrm{C}$. We report a new gas-medium apparatus for rock deformation, presenting preliminary results as an example of test results.

\section{Introduction}

Fault zones are formed from materials with properties different from those of the rocks distributed around the fault zones. In order to understand the deformation and fluidflow processes near the base of a seismogenic region, we need to understand the deformation processes and physical properties of fault materials under high-pressure and hightemperature conditions. Although its importance is well recognized, only limited amounts of data on the deformation processes of fault materials under high-pressure and hightemperature conditions are available.

In order to obtain information in the laboratory about deformation and fluid-flow processes that occur under conditions of seismogenic regions, it is necessary to speed up the process (Paterson, 1990). This may be done by increasing either the temperature or the stress difference applied to a sample or increasing both. The temperatures in experiments aimed at deformation and fluid-flow processes in seismogenic regions must be as high as possible without melting or otherwise exceeding the stability limits of the specimen material. This qualification often limits temperatures to around 1000 K (Paterson, 1990). In experimental deformation studies, samples are usually heated by either an external furnace (outside the pressure vessel) or an internal furnace (inside the pressure vessel). The external furnace is, however, limited to $500^{\circ} \mathrm{C}$. Liquids, weak solids or gases can be used as the confining pressure medium. However, liquid systems have a disadvantage in that they cannot be used for temperatures above $500^{\circ} \mathrm{C}$. Solid media systems can be used for higher temperatures, but their stress accuracy is not high. Hence, we used argon gas as a pressure medium. We designed an internal furnace which achieves a maximum temperature of $800^{\circ} \mathrm{C}$ at a maximum confining pressure of $200 \mathrm{MPa}$. The gas apparatus, which incorporates an internal furnace with an internal

Copy right(c) The Society of Geomagnetism and Earth, Planetary and Space Sciences (SGEPSS); The Seismological Society of Japan; The Volcanological Society of Japan; The Geodetic Society of Japan; The Japanese Society for Planetary Sciences. force gauge, were built by Heard (Heard and Carter, 1968), Paterson (1970), and others. We constructed the Japanesetype gas-medium apparatus that was originally designed by Prof. T. Shimamoto of Kyoto University (e.g. Wibberley and Shimamoto, in press). We adopted his basic design for the high-pressure gas system and added our originally designed internal furnace.

Herein we report a new Japanese gas-medium apparatus for rock deformation and present preliminary results as an example of test results.

\section{New Gas-Apparatus Constructed}

A pressure vessel of cylindrical shape, $530 \mathrm{~mm}$ long, with an outer diameter of $230 \mathrm{~mm}$ and an inner diameter of 60 $\mathrm{mm}$ is vertically mounted in a loading frame. The axial load is applied with a 270 ton hydraulically-operated actuator and a control unit, permitting servocontrol via either displacement or load. The force on the pistons due to the confining pressure alone is compensated by additionally applying the confining pressure on the loading piston, so that the loading system is only needed to apply the differential load. Running water cools the outside of the pressure vessel during experiments. Mechanical and environmental data are recorded with a digital recorder.

Argon gas is used as a pressure medium. Confining pressures up to $200 \mathrm{MPa}$ can be applied and controlled by the servocontrol. Although maximum pressure conditions were limited this time by Japanese government regulations, the controlling system for confining pressure and pore pressure is better than that for the gas rigs in other countries. Figure 1 shows the system diagram of the pressure controlling system originally designed by Prof. T. Shimamoto. A photograph of our system is shown in Masuda and Fujimoto (2001). Confining pressure is increased by two-stage intensifiers, CP1 and CP2. CP1 injects argon gas from a gas bottle, B1 or B2, into the system. Confining pressure is increased to $80 \mathrm{MPa}$ in less than 10 minutes at this first stage. CP1 is then detached from the system by closing valve \#4. Then, the system pres- 


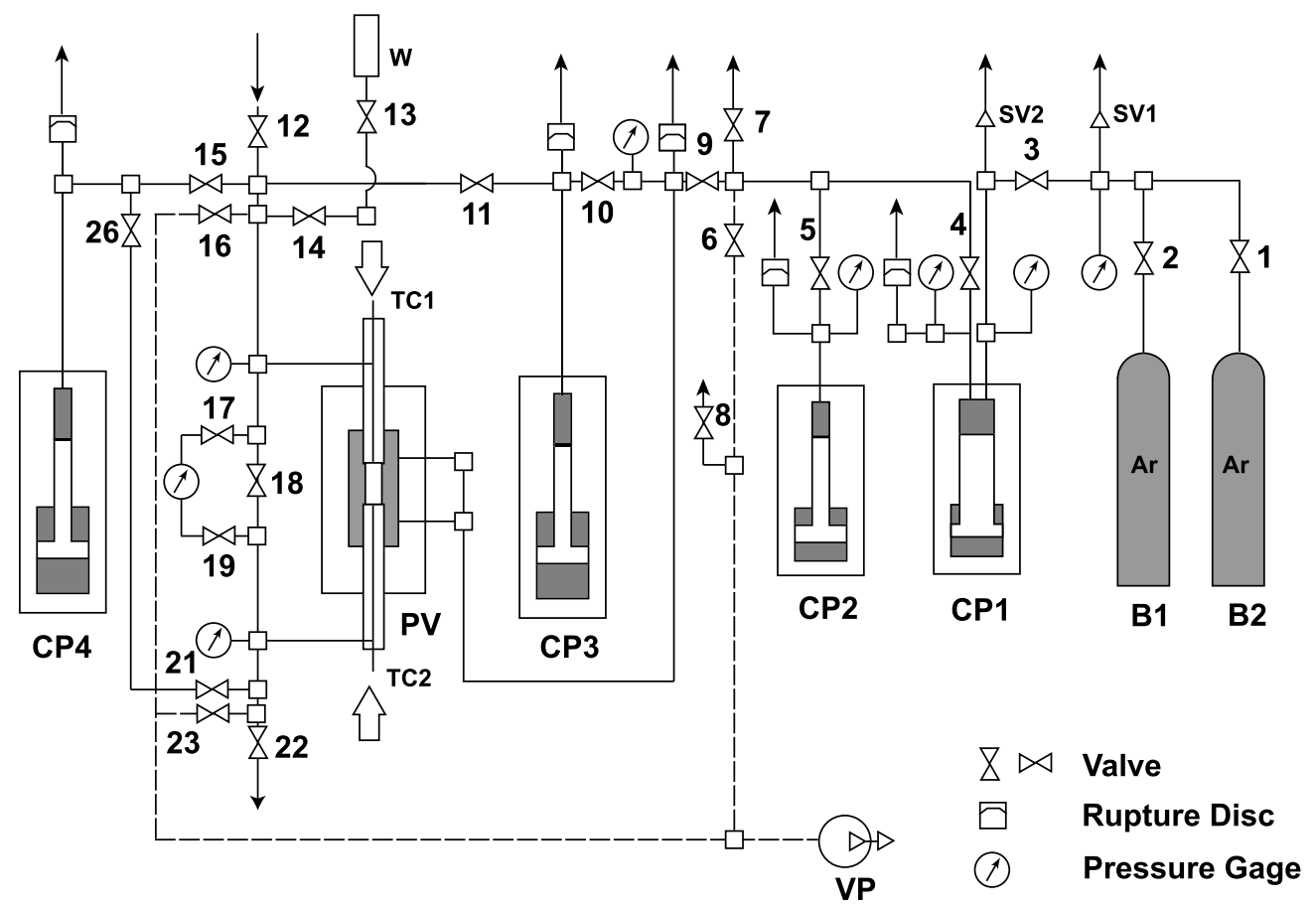

Fig. 1. System diagram. B1, B2: argon gas bottles, SV1, SV2: safety valve, CP1: pressure generator, CP2: pressure intensifiers, CP3: servocontrolled intensifier for confining pressure, CP4: servocontrolled intensifier for pore pressure, PV: pressure vessel, VP: vacuum pump, TC1, TC2: thermocouples, W: water tank.

sure is increased by CP2 from $80 \mathrm{MPa}$ to maximum $200 \mathrm{MPa}$ in a single stroke. CP2 is then detached from the system by closing valve \#5. During the experiment, including the temperature increase stage, confining pressure is adjusted by the large-volume servocontrolled intensifier CP3.

Pore pressures up to $200 \mathrm{MPa}$ are designed to be applied to the specimen through axial holes in the upper and the lower loading pistons. Either argon gas or water can be used for the pore pressure medium. An independent servocontrolled intensifier, $\mathrm{CP} 4$, controls either pore fluid pressure or fluid flow volume under the controlled confining pressure condition.

\section{Sample and Furnace Configuration}

The system is designed to handle a cylindrical sample of $40 \mathrm{~mm}$ length and either $20 \mathrm{~mm}$ or $16 \mathrm{~mm}$ diameter with a 2-mm-thick graphite sleeve. The furnace configuration and a $16 \mathrm{~mm}$ diameter sample encased in a graphite sleeve are shown in Fig. 2. The cylindrical sample and sleeve are inserted into a $0.25 \mathrm{~mm}$ thick annealed copper tube; the graphite sleeve acts as a buffer to prevent the jacket from rupturing (Stesky et al., 1974; Ohnaka et al., 1997). Tungsten carbide (WC) spacers minimize the temperature gradient across the sample. Alumina spacers prevent excess heat from escaping through the ends of the column.

A two-zone internal furnace is mounted vertically. Independent control of power to the two zones of the windings enables control of the temperature distribution to the $40 \mathrm{~mm}$ sample. Two thermocouples are inserted through the holes in the upper and lower pistons to the points just above and below the sample. The thermocouple signals monitoring the temperature of the upper and lower surfaces of the sample are recorded and used as feedback for operation of automatic

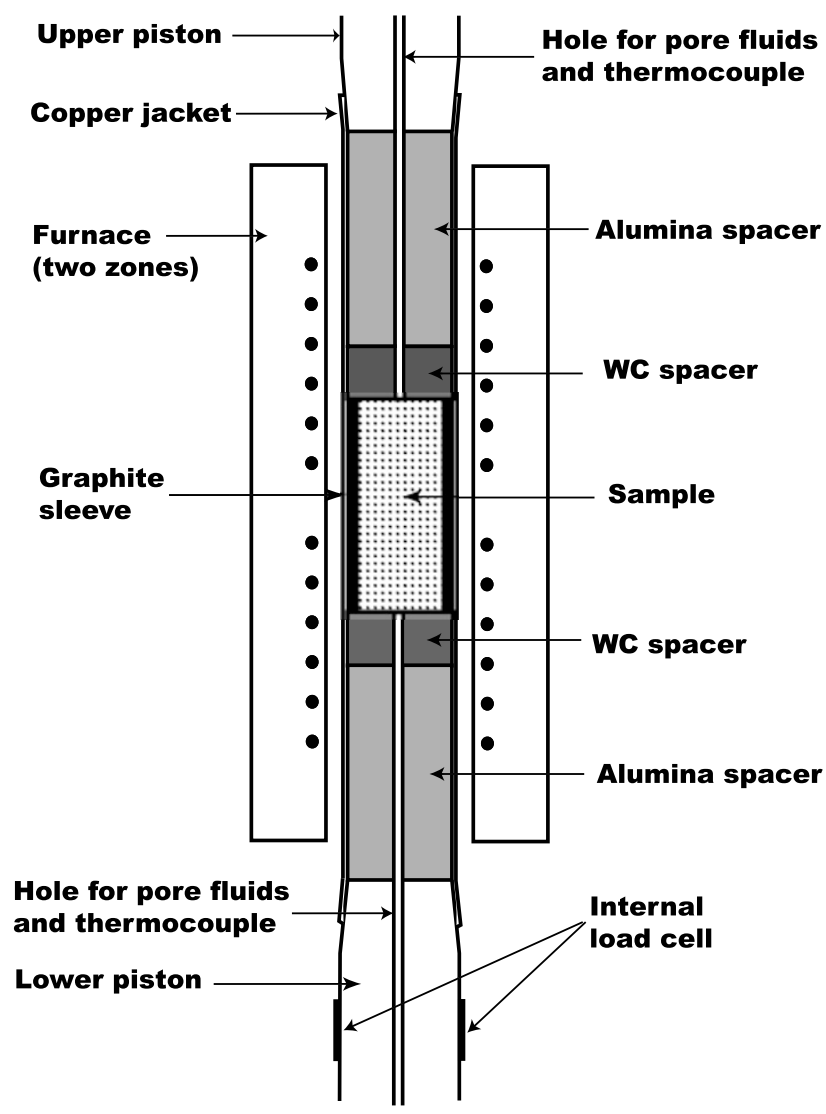

Fig. 2. Sample and furnace configuration. 
temperature controllers. The gap between the furnace bore and the copper jacket above the hot zone is filled with insulating materials that serve to restrict convection of the argon gas. Two thermocouples are installed inside the furnace case in order to monitor the temperature of the pressure vessel wall. The temperature of the pressure vessel wall should be maintained at less than $300^{\circ} \mathrm{C}$ even though the sample temperature is much higher. Another thermocouple monitors the temperature around the internal load cell mounted on the lower piston.

Two pairs of heater feed-throughs, an eight-unit thermocouple feed-through for in-vessel temperature monitoring, and an eight-unit feed-through for the internal load cell are located in the lower piston's platen. Two sets of eight-unit feed-throughs have also been created for future uses, such as elastic-wave velocity and electrical conductivity measurements.

\section{Stress-Strain Measurement}

The axial force can be measured both with an external load cell, installed in the load actuator, and with an internal load cell, consisting of a bridge of four electric-resistance strain gauges mounted integrally on the lower-loading piston, the distortion of which is measured by them. In the case of the external load cell, correction is needed for friction. With the internal load cell, no friction correction is needed.

The piston displacement is measured with a linear variable differential transformer (LVDT) fitted to the load actuator outside the pressure vessel during the tests. Output signals from the LVDT were corrected for integrated elastic deformation of the upper and lower loading pistons and the inserted spacers during the experiments. The correction curve was obtained by using a dummy specimen ( $\mathrm{SiC}$ ) whose elastic constants are known, in place of a rock sample under the ambient condition, under $100 \mathrm{MPa}$ confining pressure both at room temperature and at $400^{\circ} \mathrm{C}$. No significant difference was observed between these test results.

We used a homogeneous granite block and a mylonite block as starting materials for our experiments. The granite sample was a very homogeneous Indian granite with grain size of about $0.3-0.5 \mathrm{~mm}$, the same as the granite sample used in the series of well-controlled experiments of Masuda (2001). The mylonite sample was taken from the Hatagawa fault zone, northeast Japan (Shigematsu and Tanaka, 2000; Takagi et al., 2000). All samples from the granitic and the mylonite blocks were cored in the same direction. This procedure allowed us to obtain core samples with almost the same physical properties and provide a high level of replication under controlled test conditions. The sample shape was a cylinder of $16.0 \mathrm{~mm}$ diameter and $40.0 \mathrm{~mm}$ length (diameter-length ratio is 1:2.5). The end surfaces were made parallel to within $2 / 100 \mathrm{~mm}$. The sample axis of the mylonite samples was 30 degrees from the orientation of the foliation structure of the mylonite block. That way, when we applied differential stress to the mylonite sample, the shear stress acted on the plane parallel to the foliation structure and in the same orientation of the shear stress that the mylonite block suffered when it was formed. All samples were room dried before the tests. In this report, we present our preliminary results as an example of test results. A full description of the results of the tests will be reported in another paper.

We carried out a series of conventional triaxial compression tests at a constant displacement rate. The strain rate of deformation was $5.5 \times 10^{-6} / \mathrm{s}$; the temperature was raised at a rate of $10^{\circ} \mathrm{C} / \mathrm{min}$ for all experiments reported in this paper.

Figure 3 shows the stress-strain curves of mylonite samples under dry and wet conditions at the same effective confining pressure of $130 \mathrm{MPa}$ at a temperature of $600^{\circ} \mathrm{C}$. In the dry condition, a confining pressure of $130 \mathrm{MPa}$ was applied. In the wet condition, pore pressure of $70 \mathrm{MPa}$ was applied by pure water under a confining pressure of $200 \mathrm{MPa}$. Even under the same effective confining pressure, the presence of water dramatically reduced the peak shear stress in the hightemperature regime. Fluids such as water in the deep crust may play an important role in deformation and fracture processes (e.g. Seno et al., 2001; Zhao et al., 2001).

Figure 4 shows the stress-strain curves of both mylonite and granite samples under the same dry condition of 200 $\mathrm{MPa}$ confining pressure at $800^{\circ} \mathrm{C}$. Both samples show ductile behavior. The yield stress of the mylonite sample is much

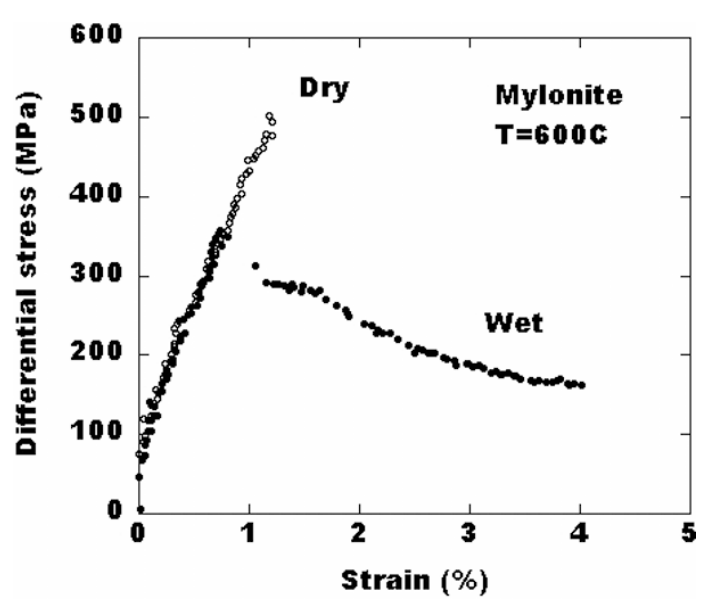

Fig. 3. Stress-strain curves of mylonite samples under dry $(130 \mathrm{MPa}$ confining pressure) and wet (200 MPa confining pressure and $70 \mathrm{MPa}$ pore pressure) conditions at $600^{\circ} \mathrm{C}$. Effective confining pressure is 130 $\mathrm{MPa}$ for both dry and wet conditions.

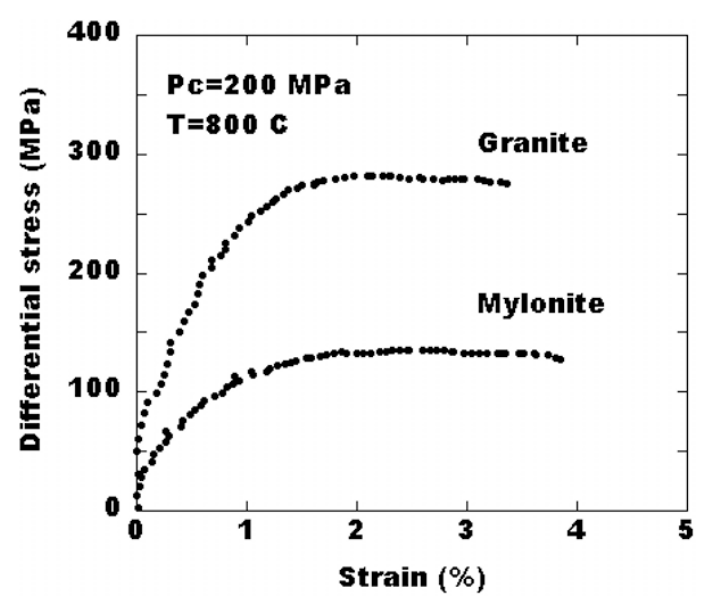

Fig. 4. Stress-strain curves of granite and mylonite samples under $200 \mathrm{MPa}$ confining pressure at $800^{\circ} \mathrm{C}$. 
smaller than that of the granite sample. The internal structure of fault rocks such as foliation structure may significantly affect the deformation and/or fluid-flow processes in a highpressure and high-temperature regime such as a seismogenic region. The gas-medium apparatus is suitable to this kind of study on the influence of temperature on the deformation and fluid-flow processes of rocks (e.g. Tullis and Tullis, 1986).

Acknowledgments. Technical advice from Prof. T. Shimamoto of Kyoto University and technical works of K. Iryo and the staff of SE Co. Ltd. and M. Yamada and the staff of Saginomiya Co. were very helpful in constructing the gas-medium high-pressure, high-temperature apparatus. We also thank N. Shigematsu and Y. Kobayashi for collecting the mylonite samples used in this study. Reviews of Profs. T. Shimamoto and B. Hobbs were very helpful in improving the manuscript.

\section{References}

Heard, H. C. and N. Carter, Experimentally induced "natural" intragranular flow in quartz and quartzite, Am. J. Sci., 266, 1-42, 1968.

Masuda, K., Effects of water on rock strength in the brittle regime, J. Struct. Geol., 23, 1653-1657, 2001.

Masuda, K. and K. Fujimoto, Friction, deformation, and flow experiments of fault materials under high-temperature and high-pressure, Chikyu Monthly, 23, 328-331, 2001 (in Japanese).

Ohnaka, M., M. Akatsu, H. Mochizuki, A. Odedra, F. Tagashira, and Y. Yamamoto, A constitutive law for the shear failure of rock under litho- spheric conditions, Tectonophys., 277, 1-27, 1997.

Paterson, M. S., A high-pressure, high-temperature apparatus for rock deformation, Int. J. Rock Mech. Min. Sci., 7, 517-526, 1970.

Paterson, M. S., Rock deformation experimentation, in The Brittle-Ductile Transition in Rocks, The Heard Volume, Geophysical Monograph 56, AGU, 187-194, 1990.

Seno, T., D. Zhao, Y. Kobayashi, and M. Nakamura, Dehydration of serpentinized slab mantle: Seismic evidence from southwest Japan, Earth Planets Space, 53, 861-871, 2001.

Shigematsu, N. and H. Tanaka, Dislocation creep of fine-grained recrystallized plagioclase under low-temperature conditions, J. Struct. Geol., 22, 65-79, 2000

Stesky, R. M., W. F. Brace, D. K. Riley, and P.-Y. F. Robin, Friction in faulted rock at high temperature and pressure, Tectonophys., 23, 177203, 1974

Takagi, H., K. Goto, and N. Shigematsu, Ultramylonite bands derived from cataclasite and pseudotachylyte in granite, northeast Japan, J. Struct. Geol., 22, 1325-1339, 2000

Tullis, T. and J. Tullis, Experimental rock deformation techniques, in Mineral and Rock Deformation: Laboratory Studies, Geophysical Monograph 36, AGU, 297-324, 1986.

Wibberley, C. A. J. and T. Shimamoto, Internal structure and permeability of major strike-slip zones: the Median Tectonic Line in Mie Prefecture, Southwest Japan, J. Struct. Geol., 25, 59-78, 2003 (in press).

Zhao, D., K. Wang, G. C. Rogers, and S. M. Peacock, Tomographic image of low P velocity anomalies above slab in northern Cascadia subduction zone, Earth Planets Space, 53, 285-293, 2001.

K. Masuda (e-mail: koji.masuda@aist.go.jp), K. Fujimoto, and T. Arai 